\title{
Barotropic Processes Associated with the Development of the Mei-yu Precipitation System
}

\author{
Tingting LI and Xiaofan LI* \\ School of Earth Sciences, Zhejiang University, Hangzhou 310027
}

(Received 15 June 2015; revised 3 November; accepted 9 November 2015)

\begin{abstract}
The barotropic processes associated with the development of a precipitation system are investigated through analysis of cloud-resolving model simulations of Mei-yu torrential rainfall events over eastern China in mid-June 2011. During the model integration period, there were three major heavy rainfall events: 9-12, 13-16 and 16-20 June. The kinetic energy is converted from perturbation to mean circulations in the first and second period, whereas it is converted from mean to perturbation circulations in the third period. Further analysis shows that kinetic energy conversion is determined by vertical transport of zonal momentum. Thus, the prognostic equation of vertical transport of zonal momentum is derived, in which its tendency is associated with dynamic, pressure gradient and buoyancy processes. The kinetic energy conversion from perturbation to mean circulations in the first period is mainly associated with the dynamic processes. The kinetic energy conversion from mean to perturbation circulations in the third period is generally related to the pressure gradient processes.
\end{abstract}

Key words: tropical cyclone-trough interaction, upper troposphere, eddy momentum flux convergence

Citation: Li, T. T., and X. F. Li, 2016: Barotropic processes associated with the development of the Mei-yu precipitation system. Adv. Atmos. Sci., 33(5), 593-598, doi: 10.1007/s00376-015-5146-z.

\section{Introduction}

Barotropic processes represent one of the most important physical process types in the development of precipitation systems. They are described by the kinetic energy conversion between the mean background circulations and perturbation (secondary) circulations associated with vapor condensation and deposition for the production of precipitation. Such kinetic energy conversion is primarily determined by vertical transport of horizontal momentum acting on vertical shear of the mean background horizontal winds (e.g., Pastushkov, 1975). Barotropic processes may affect the development of precipitation systems through the vertical wind shear of background circulations (e.g., Corbosiero and Molinari, 2002; Lang et al., 2007; Ueno, 2007). The vertical wind shear may have impacts on the timing of convection ( $\mathrm{Xu}$ et al., 1992), the organization of convection (Robe and Emanuel, 2001) and rainfall (e.g, Wang et al., 2009; Shen et al., 2011).

Severe floods and associated natural disasters occur in the Mei-yu season as torrential rainfall frequently occurs over the middle and lower reaches of the Yangtze River during the early season of the NH summer. Zhai et al. (2014) conducted a cloud-resolving model study of a Mei-yu heavy rainfall event that occurred over eastern China in mid-June 2011. During the modeling period, there were three major rainfall

\footnotetext{
* Corresponding author: Xiaofan LI

Email: xiaofanli@zju.edu.cn
}

events, and they found differences in rainfall types and horizontal scale between the three periods. Wu and Yanai (1994) revealed the effects of vertical wind shear on the development of a precipitation system through the change in vertical transport of horizontal momentum. But does vertical wind shear determine barotropic kinetic energy conversion directly through the change in vertical transport of horizontal momentum? And which physical processes control vertical transport of horizontal momentum?

The objective of this study is to examine the barotropic processes associated with the Mei-yu precipitation system through analysis of the differences in barotropic processes between three rainfall events using the Mei-yu simulation data from Zhai et al. (2014). The model, large-scale forcing, and sensitivity experiments are briefly described in section 2 . The results are presented in section 3. A summary is given in section 4 .

\section{Model and experiments}

The experiment analyzed in this study was conducted by Zhai et al. (2014) using the 2D version of a cloud-resolving model (Table 1). The model was integrated with imposed large-scale forcing from 0800 LST 9 June to 0800 LST 20 June 2011. The forcing was averaged in a rectangular box of $\left(30^{\circ}-31^{\circ} \mathrm{N}, 114^{\circ}-122^{\circ} \mathrm{E}\right)$ using NCEP/GDAS data. There are three upward motion centers while westerly winds pre- 
vail (Zhai et al., 2014, Fig. 1). The three torrential rainfall events are forced by the three upward motion centers during the model integration period (Fig. 1). The rainbands are better organized in the third rainfall event than in the two previous rainfall events, while the second rainfall event occupies a larger area than the two other rainfall events. Thus, the model integration period is divided into the three subperiods: 0800 LST 9 June to 0000 LST 13 June (the first period); 0000 LST 13 June to 1200 LST 16 June (the second period); and 1200 LST 16 June to 0800 LST 20 June (the third period). The large-scale forcing is averaged for the three periods and shown in Fig. 2. The averaged vertical profiles show that westerly winds generally increase with increasing height (Fig. 2a). Near the surface, averaged zonal winds are zero in the first period and weak easterly winds in the two other periods. In the upper troposphere, the westerly winds in the first period are stronger than in the third period, whereas they are weaker in the second period. The averaged upward motions prevail in the troposphere and reach their maxima around 8 $\mathrm{km}$ (Fig. 2b). Below $10 \mathrm{~km}$, the averaged upward motions in the third period are stronger than in the first period, but they are weaker than in the second period. Above $10 \mathrm{~km}$, the averaged upward motions in the first period are stronger than in the third period, but they are weaker than in the second period. The averaged rain rates are $0.98 \mathrm{~mm} \mathrm{~h}^{-1}$ in the first period, $1.38 \mathrm{~mm} \mathrm{~h}^{-1}$ in the second period, and $1.17 \mathrm{~mm} \mathrm{~h}^{-1}$ in the third period. The rainfall is stronger in the second period than in the two other periods due to stronger upward motions in the second period. The rain rate is about $20 \%$ higher in the third period than in the first period, while the upward motions are only slightly stronger in the third period. The difference in vertical wind shear implies barotropic effects on Mei-yu rainfall.

\section{Results}

Following Li et al. (2002b), barotropic conversion between the mean kinetic energy to perturbation kinetic energy can be symbolically expressed by the sum of $C_{u}\left(\bar{K}, K^{\prime}\right)$ and $C_{w}\left(\bar{K}, K^{\prime}\right)$, where

$$
C_{u}\left(\bar{K}, K^{\prime}\right)=-\left[\overline{u^{\prime} w^{\prime}} \frac{\partial \bar{u}_{\mathrm{o}}}{\partial z}\right],
$$

and

$$
C_{w}\left(\bar{K}, K^{\prime}\right)=-\left[\overline{w^{\prime} w^{\prime}} \frac{\partial \bar{w}_{\mathrm{o}}}{\partial z}\right],
$$

in which $u$ and $w$ are the zonal and vertical components of wind, respectively; an overbar indicates the model domain mean; a prime indicates a perturbation from the model domain mean; the subscript ${ }_{0}$ is an imposed value from NCEP/ GDAS; $[\cdot]=\int_{z_{\mathrm{b}}}^{z_{\mathrm{t}}} \bar{\rho} \cdot d z$ and $\rho$ is height-dependent air density, $z_{\mathrm{t}}$ and $z_{\mathrm{b}}$ are the heights of the top and the bottom of the model atmosphere, respectively. $C_{u}\left(\bar{K}, K^{\prime}\right)$ and $C_{w}\left(\bar{K}, K^{\prime}\right)$ are the barotropic conversions between the mean domain mean kinetic energy $(\bar{K})$ and $K^{\prime}$, respectively, through vertical transport of zonal momentum acting on the vertical shear

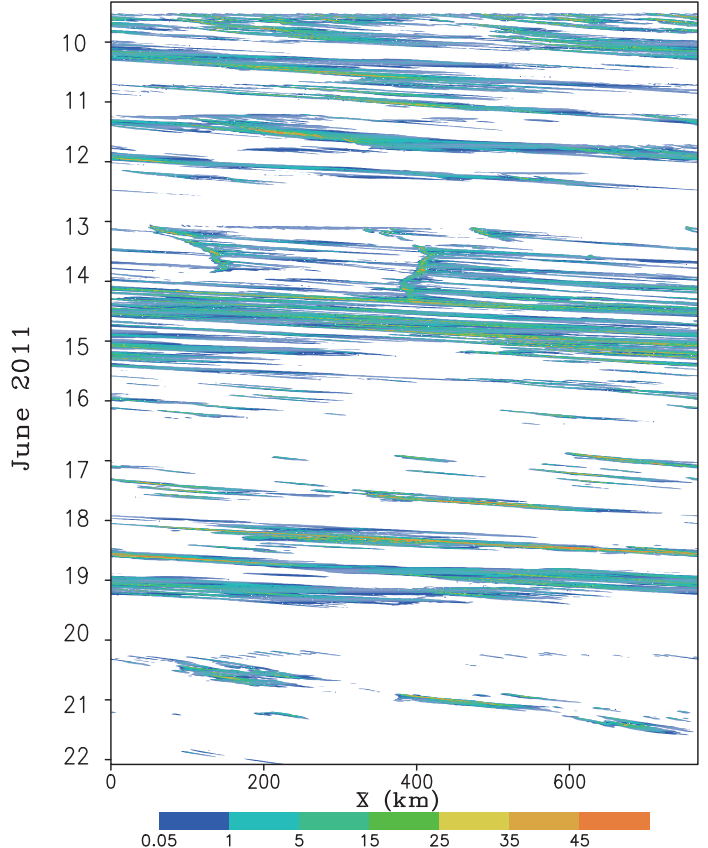

Fig. 1. Time-zonal distribution of simulated surface rainfall rate $\left(\mathrm{mm} \mathrm{h}^{-1}\right)$.

of imposed horizontal-mean zonal wind, and vertical transport of vertical momentum acting on the vertical shear of imposed horizontal-mean vertical velocity. Since the calculations from Wang et al. (2009) and Shen et al. (2011) indicate $C_{w}\left(\bar{K}, K^{\prime}\right)$ is negligible, the barotropic conversion from the mean kinetic energy to perturbation kinetic energy term can be simplified to

$$
\begin{aligned}
C_{u}\left(\bar{K}, K^{\prime}\right) & =-\left[\overline{u^{\prime} w^{\prime}} \frac{\partial \bar{u}_{\mathrm{o}}}{\partial z}\right] \\
& =-\int_{z_{\mathrm{b}}}^{z_{\mathrm{t}}}\left(\bar{\rho} \overline{u^{\prime} w^{\prime}} \frac{\partial \bar{u}_{\mathrm{o}}}{\partial z}\right) d z-\int_{z_{\mathrm{b}}}^{z_{\mathrm{t}}} \bar{\rho} \overline{u^{\prime} w^{\prime}} d \bar{u}_{\mathrm{o}} .
\end{aligned}
$$

To examine the contribution from height-dependent kinetic energy conversion to $C_{u}\left(\bar{K}, K^{\prime}\right)$, we calculate the vertical profile of barotropic kinetic energy conversion (BKEC), which can be written as:

$$
\begin{aligned}
& \mathrm{BKEC}=\mathrm{BKEC} 1 \times \mathrm{BKEC} 2 ; \\
& \mathrm{BKEC} 1=d \bar{u}_{o} ; \\
& \mathrm{BKEC} 2=-\rho \overline{u^{\prime} w^{\prime}} .
\end{aligned}
$$

Here, BECK1 is the vertical difference in zonal wind, and BKEC2 is the air density weighted covariance between perturbation zonal wind and vertical velocity or vertical transport of zonal momentum. $C_{u}\left(\bar{K}, K^{\prime}\right)$ is calculated by vertically integrating BKEC or adding BKEC for all vertical layers in our calculations.

The calculations of BKEC show that the BKEC is generally negative in the troposphere in the first period (Fig. 3a). In the second period, the BKEC is positive below $4 \mathrm{~km}$ but negative above $4 \mathrm{~km}$ (Fig. 3b). The BKEC is generally positive from 1 to $9 \mathrm{~km}$ (Fig. 3c). Since negative and positive 
Table 1. Model setup.

\begin{tabular}{|c|c|}
\hline Model property & Description \\
\hline Model history & $\begin{array}{l}\text { Originally developed by Soong and Ogura (1980), Soong and Tao (1980) and Tao and Simpson (1993), } \\
\text { and modified by Sui et al. }(1994,1998) \text { and Li et al. }(1999,2002 \mathrm{a})\end{array}$ \\
\hline Prognostic equations & $\begin{array}{l}\text { Potential temperature, specific humidity, perturbation zonal wind and vertical velocity, and mixing ratios } \\
\text { of five cloud species }\end{array}$ \\
\hline Cloud microphysical schemes & Lin et al. (1983), Rutledge and Hobbs $(1983,1984)$, Tao et al. (1989) and Krueger et al. (1995) \\
\hline Radiation schemes & Chou et al. $(1991,1998)$ and Chou and Suarez (1994) \\
\hline Boundary conditions & Cyclic lateral boundaries and model top at $42 \mathrm{hPa}$ \\
\hline Basic parameter set & Model domain $(768 \mathrm{~km})$, horizontal grid mesh $(1.5 \mathrm{~km})$, time step $(1.5 \mathrm{~s})$, and 33 vertical levels \\
\hline Large-scale forcing & Vertical velocity, zonal wind, surface fluxes and horizontal advections \\
\hline References & Gao and $\mathrm{Li} \mathrm{(2008)} \mathrm{and} \mathrm{Li} \mathrm{and} \mathrm{Gao} \mathrm{(2012)}$ \\
\hline
\end{tabular}
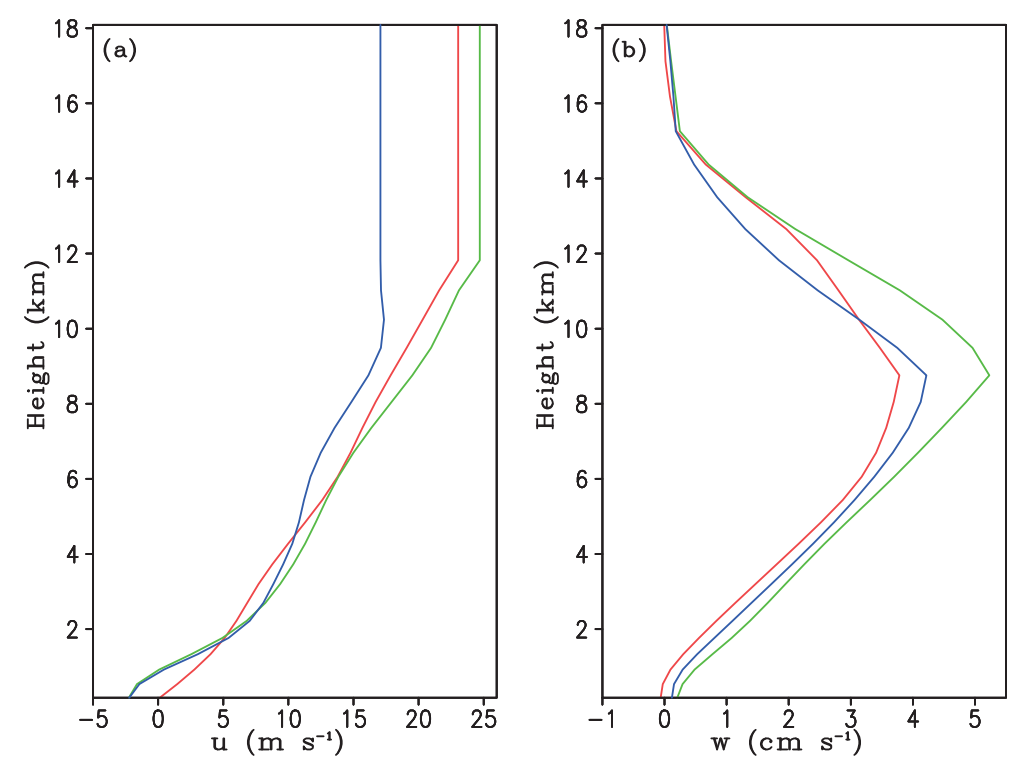

Fig. 2. Vertical profiles of (a) zonal wind $\left(\mathrm{m} \mathrm{s}^{-1}\right)$ and (b) vertical velocity (cm $\mathrm{s}^{-1}$ ) averaged from 0800 LST 9 June to 0000 LST 13 June (red), from 0000 LST 13 June to 1200 LST 16 June (green) and from 1200 LST 16 June to 0800 LST 20 June (blue).

BKEC values indicate kinetic energy conversion from perturbation to mean circulation and from mean to perturbation circulation, respectively, the positive BKEC value denotes a dynamically unstable system and the negative BKEC value represents a dynamically stable system. Thus, the precipitation system is dynamically stable in the first and second periods and dynamically unstable in the third period.

The BKEC is associated with the vertical shear of imposed zonal wind (BKEC1) and the vertical transport of zonal momentum (BKEC2), which are time-dependent. Thus, the time-mean BKEC (BKEC hereafter) can be decomposed into the two components

$$
\mathrm{BKEC}_{\mathrm{M}}=\mathrm{BKEC}_{\mathrm{M}} \times \mathrm{BKEC}_{\mathrm{M}},
$$

and

$$
\mathrm{BKEC}_{\mathrm{T}}=\mathrm{BKEC}_{\mathrm{T}} \times \mathrm{BKEC}_{\mathrm{T}},
$$

where $B K E C 1_{M}$ and $B K E C 2_{M}$ are the time averages of $\mathrm{BKEC} 1$ and $\mathrm{BKEC} 2$, respectively, and $\mathrm{BKEC}_{\mathrm{T}}$ and $\mathrm{BKEC}_{\mathrm{T}}$ are the deviations of BKEC1 and BKEC2 from $B K E C 1_{M}$ and $B K E C 2_{M}$, respectively. In general, $B K E C_{M}$ is out of phase with $\mathrm{BKEC}_{\mathrm{T}}$ vertically. $\mathrm{BKEC}_{\mathrm{M}}$ is negative but $\mathrm{BKEC}_{\mathrm{T}}$ is positive through the troposphere in the first period (Fig. 3a). BKEC is controlled by $\mathrm{BKEC}_{\mathrm{M}}$. In the second period, $\mathrm{BKEC}_{\mathrm{M}}$ is negative from 2 to $8 \mathrm{~km}$ (Fig. $3 \mathrm{~b}$ ). $\mathrm{BKEC}_{\mathrm{T}}$ is negative above $7 \mathrm{~km}$, whereas it is positive below $7 \mathrm{~km}$. The negative $\mathrm{BKEC}$ is associated with the negative $\mathrm{BKEC}_{\mathrm{T}}$ above $8 \mathrm{~km}$ and $\mathrm{BKEC}_{\mathrm{M}}$ from 4 to $8 \mathrm{~km}$. The positive $\mathrm{BKEC}$ corresponds to the positive $\mathrm{BKEC}_{\mathrm{T}}$ below $4 \mathrm{~km}$. In the third period, $\mathrm{BKEC}_{\mathrm{M}}$ is positive throughout the troposphere (Fig. $3 \mathrm{c})$. BKEC $_{\mathrm{T}}$ is negative above $5 \mathrm{~km}$ but it is positive below $5 \mathrm{~km}$. The positive BKEC is determined by the positive BKEC $_{\mathrm{M}}$.

Since BKEC is controlled by $\mathrm{BKEC}_{\mathrm{M}}$, the time-mean BKEC1 and BKEC2 are analyzed (Fig. 4). The imposed zonal winds increase with increasing height in the three periods (Fig. 4a). The time-mean vertical wind shear (BKEC1) barely changes in the first period. The time-mean vertical wind shear is similar in the second and third period, except that the vertical wind shear is decreased to zero around 12 $\mathrm{km}$ in the second period but around $10 \mathrm{~km}$ in the third period. In the second and third period, the vertical wind shear reaches 

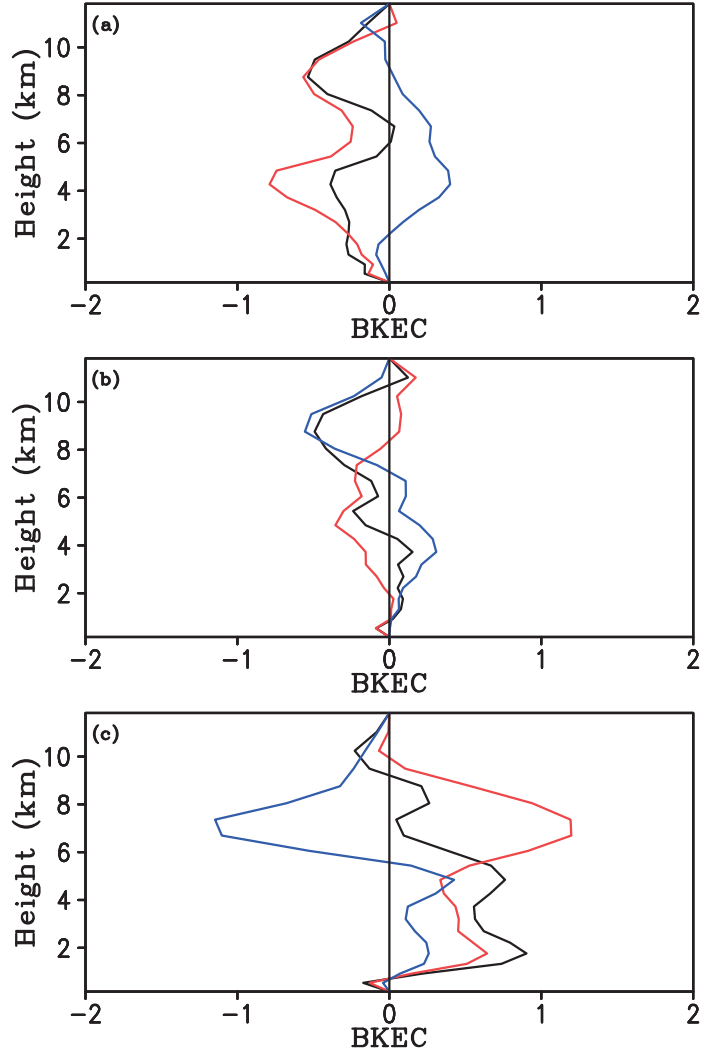

Fig. 3. Vertical profiles of barotropic kinetic energy conversion (BKEC; black) and its components $\left(\mathrm{BKEC}_{\mathrm{M}}\right.$, red; $\mathrm{BKEC}_{\mathrm{T}}$, blue) averaged (a) from 0800 LST 9 June to 0000 LST 13 June, (b) from 0000 LST 13 June to 1200 LST 16 June, and (c) from 1200 LST 16 June to 0800 LST 20 June. Units: $10^{5} \mathrm{~J} \mathrm{~s}^{-1}$.

its peak near the surface, reduces in magnitude around $4 \mathrm{~km}$, and reaches a sub-peak at around $8 \mathrm{~km}$. Since the timemean vertical wind shear has the same sign in all three periods, the differences in $\mathrm{BKEC}_{\mathrm{M}}$ between the three periods are attributable to the differences in BKEC2. The timemean BKEC2 changes from negative values (upward zonalmomentum transport) in the first and second period to positive values (downward zonal-momentum transport) in the third period, through a significant increase in positive BKEC2 from the first and second period to the third period (Fig. 4b). Thus, the dynamic stability $\left(\mathrm{BKEC}_{\mathrm{M}}\right)$ of the precipitation system is determined by BKEC2 in this Mei-yu precipitation system.

To further investigate if the vertical wind shear directly affects the BKEC2, or through which physical factors if the vertical wind shear indirectly affects the BKEC2, the tendency equation of BKEC2 is derived from the perturbation momentum equations. Following Li et al. (2002b), the perturbation momentum equations in the $2 \mathrm{D}$ cloud-resolving model can be written by:

$$
\begin{aligned}
\frac{\partial u^{\prime}}{\partial t}= & -\frac{\partial}{\partial x}\left(2 u^{\prime} \bar{u}_{\mathrm{o}}+u^{\prime} u^{\prime}\right)- \\
& \frac{1}{\bar{\rho}} \frac{\partial}{\partial z} \bar{\rho}\left(w^{\prime} \bar{u}_{\mathrm{o}}+\bar{w}_{\mathrm{o}} u^{\prime}+w^{\prime} u^{\prime}-\overline{w^{\prime} u^{\prime}}\right)-c_{p} \frac{\partial\left(\bar{\theta} \pi^{\prime}\right)}{\partial x} ;
\end{aligned}
$$
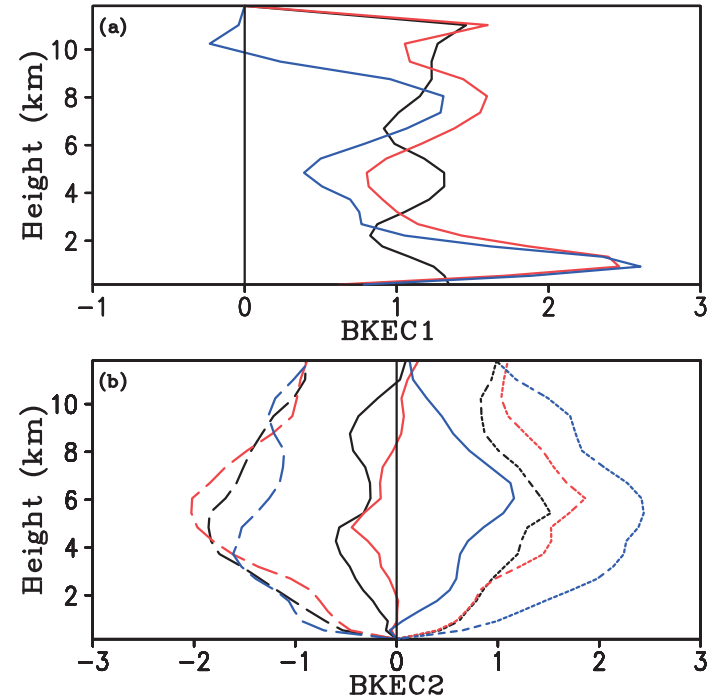

Fig. 4. Vertical profiles of (a) imposed zonal-wind difference in the vertical layer $\left(d \bar{u}_{\mathrm{o}}\right.$; BKEC1; $\left.\mathrm{m} \mathrm{s}^{-1}\right)$ and (b) air density weighted covariance between perturbation zonal wind and vertical velocity ( $-\bar{\rho} \overline{u^{\prime} w^{\prime}}$; BKEC2; $10^{5} \mathrm{~J} \mathrm{~m}^{-1}$; solid lines) averaged from 0800 LST 9 June to 0000 LST 13 June (black), from 0000 LST 13 June to 1200 LST 16 June (red), and from 1200 LST 16 June to 0800 LST 20 June (blue). In (b), BKEC2 is broken into components for $u^{\prime} w^{\prime}>0$ (long-dashed line) and $u^{\prime} w^{\prime}<0$ (short-dashed line).

$$
\begin{aligned}
\frac{\partial w^{\prime}}{\partial t}= & -\frac{\partial}{\partial x}\left(u^{\prime} \bar{w}_{\mathrm{o}}+\bar{u}_{\mathrm{o}} w^{\prime}+u^{\prime} w^{\prime}\right)- \\
& \frac{1}{\bar{\rho}} \frac{\partial}{\partial z} \bar{\rho}\left(2 w^{\prime} \bar{w}_{\mathrm{o}}+w^{\prime} w^{\prime}-\overline{w^{\prime} w^{\prime}}\right)- \\
& c_{p} \frac{\partial\left(\bar{\theta} \pi^{\prime}\right)}{\partial z}+g\left(\frac{\theta^{\prime}}{\theta_{0}}+0.61 q_{v}^{\prime}-q_{l}^{\prime}\right) .
\end{aligned}
$$

Here, $\theta$ is potential temperature, and $\theta_{0}$ is initial potential temperature; $\pi=\left(p / p_{\mathrm{o}}\right)^{\kappa}$ and $\kappa=R / c_{p} ; R$ is the gas constant; $c_{p}$ is the specific heat of dry air at constant pressure $p$, where $p_{\mathrm{o}}=1000 \mathrm{hPa} ; q_{v}$ is specific humidity; and $q_{l}$ is the sum of the mixing ratios of cloud water, raindrops, cloud ice, snow and graupel.

Multiplying Eq. (5a) by $-\bar{\rho} w^{\prime}$ and Eq. (5b) by $-\bar{\rho} u^{\prime}$, adding the equations nd taking the model domain mean, the tendency equation of BKEC2 $\left(\mathrm{BKEC} 2_{\mathrm{t}}\right)$ can be expressed by

$$
\mathrm{BKEC} 2_{\mathrm{t}}=\mathrm{BKEC} 2_{\mathrm{d}}+\mathrm{BKEC} 2_{\mathrm{p}}+\mathrm{BKEC} 2_{\mathrm{b}},
$$

where

$$
\begin{aligned}
\mathrm{BKEC}_{\mathrm{t}}= & \frac{\partial}{\partial t} \mathrm{BKEC} 2=\frac{\partial}{\partial t}\left(-\bar{\rho} \overline{u^{\prime} w^{\prime}}\right), \\
\mathrm{BKEC} 2_{\mathrm{d}}= & \bar{\rho} w^{\prime} \frac{\partial}{\partial x}\left(2 u^{\prime} \bar{u}_{\mathrm{o}}+u^{\prime} u^{\prime}\right)+ \\
& \frac{w^{\prime} \frac{\partial}{\partial z} \bar{\rho}\left(w^{\prime} \bar{u}_{\mathrm{o}}+\bar{w}_{\mathrm{o}} u^{\prime}+w^{\prime} u^{\prime}\right)+}{\bar{\rho} u^{\prime} \frac{\partial}{\partial x}\left(u^{\prime} \bar{w}_{\mathrm{o}}+\bar{u}_{\mathrm{o}} w^{\prime}+u^{\prime} w^{\prime}\right)+} \\
& \frac{u^{\prime} \frac{\partial}{\partial z} \bar{\rho}\left(2 w^{\prime} \bar{w}_{\mathrm{o}}+w^{\prime} w^{\prime}\right)}{}
\end{aligned}
$$




$$
\mathrm{BKEC} 2_{\mathrm{p}}=c_{p} \overline{\bar{\rho}} w^{\prime} \frac{\partial\left(\bar{\theta} \pi^{\prime}\right)}{\partial x}+u^{\prime} \frac{\partial\left(\bar{\theta} \pi^{\prime}\right)}{\partial z},
$$

and

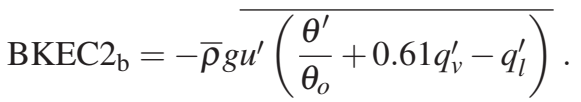

Here, $\mathrm{BKEC} 2_{\mathrm{d}}, \mathrm{BKEC} 2_{\mathrm{p}}$ and $\mathrm{BKEC} 2_{\mathrm{b}}$ are the contributors to $\mathrm{BKEC} 2_{\mathrm{t}}$ from the processes related to dynamics, the pressure gradient and buoyancy force, respectively. BKEC 2 b can be further partitioned into three terms:

$$
\begin{aligned}
& \mathrm{BKEC}_{\mathrm{b} 1}=-\bar{\rho} g \overline{u^{\prime} \frac{\theta^{\prime}}{\theta_{\mathrm{o}}}} ; \\
& \mathrm{BKEC} 2_{\mathrm{b} 2}=-0.61 \bar{\rho} g \overline{u^{\prime} q_{v}^{\prime}} ; \\
& \mathrm{BKEC}_{\mathrm{b} 3}=\bar{\rho} g \overline{u^{\prime} q_{l}^{\prime}} .
\end{aligned}
$$

The tendency budget of BKEC2 is integrated with time and each term in the budget has a contribution to BKEC2. $\mathrm{BKEC} 2_{\mathrm{p}}$ is largely balanced by $\mathrm{BKEC} 2_{\mathrm{d}}$ in the three periods, indicating the dominance of the processes related to dynamics and the pressure gradient in determining BKEC2. BKEC2 is at least three orders of magnitude smaller than these dominant terms. Negative values of BKEC2 correspond mainly to those of BKEC $2_{\mathrm{d}}$ below $8 \mathrm{~km}$ and $\mathrm{BKEC} 2_{\mathrm{p}}$ above $8 \mathrm{~km}$ in the first period (Fig. 5a), and those of BKEC $2_{\mathrm{d}}$ above $4 \mathrm{~km}$ and $\mathrm{BKEC} 2_{\mathrm{p}}$ below $4 \mathrm{~km}$ in the second period (Fig. $5 \mathrm{~b}$ ). The magnitudes of $B K E C 2_{d}$ and $B K E C 2_{p}$ decrease from the first and second periods to the third period (Fig. 5c). In the third period, positive values of BKEC2 are mainly associated with those of $\mathrm{BKEC} 2 \mathrm{p}$ in the lower and upper troposphere and $\mathrm{BKEC} 2_{\mathrm{d}}$ in the mid troposphere. BKEC $2_{\mathrm{b} 1}$ and $\mathrm{BECK} 2_{\mathrm{b} 2}$ contribute to negative values of BKEC2 in the first and second periods, whereas $\mathrm{BKEC} 2{ }_{\mathrm{b} 2}$ contribute to positive values of $\mathrm{BKEC} 2$ in the third period.

\section{Summary}

The barotropic processes associated with the development of a Mei-yu precipitation system are investigated through analysis of conversion between perturbation and mean kinetic energy. The data analyzed are from a $2 \mathrm{D}$ cloud-resolving model simulation of three Mei-yu torrential rainfall events that occurred over eastern China in mid-June 2011. The calculations of barotropic kinetic energy conversion show that the precipitation system is dynamically stable (with conversion from perturbation to mean kinetic energy) throughout the troposphere, turns to be weakly unstable in the mid and lower troposphere, and eventually becomes dynamically unstable (with conversion from mean to perturbation kinetic energy) throughout the troposphere.

The vertical wind shear in the simulation period is increased in imposed zonal winds upward, and the magnitude increases in the mid and lower troposphere from the first period to the second period and barely changes from the second period to the third period. The barotropic conversion is
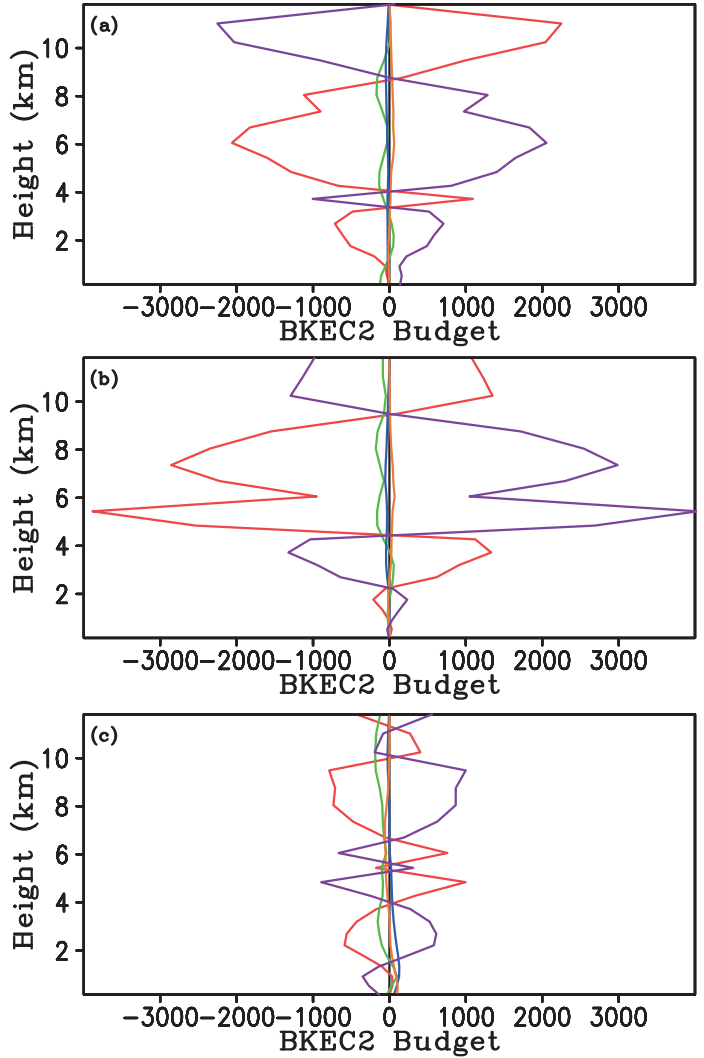

Fig. 5. Vertical profiles of BKEC2 (black) and associated contribution from $B K E C 2_{d}$ (red), $B K E C 2_{p}$ (purple), $B K E C 2_{b 1}$ (green), $\mathrm{BKEC} 2_{\mathrm{b} 2}$ (blue) and $\mathrm{BKEC} 2_{\mathrm{b} 3}$ (orange) in the $\mathrm{BKEC} 2$ budget averaged (a) from 0800 LST 9 June to 1200 LST 10 June, (b) from 0000 LST 13 June to 0000 LST 15 June, and (c) from 1200 LST 16 June to 1500 LST 18 June. Units: $10^{5}$ $\mathrm{J} \mathrm{m}^{-1}$.

determined by vertical transport of zonal momentum acting on the vertical shear of imposed mean zonal wind. Since the upward increase in zonal winds is imposed during the model integration period, the barotropic conversion is controlled by the vertical transport of zonal momentum (vertical zonal-momentum flux or covariance between perturbation zonal wind and vertical velocity). The zonal-momentum flux is changed from upward in the first and second period to downward in the third period, which leads to the change from a dynamically stable system in the first and second period to a dynamically unstable system in the third period.

An equation for predicting the vertical transport of zonal momentum is derived based on prognostic equations of perturbation zonal wind and vertical velocity. The tendency of vertical momentum flux is associated with the processes related to dynamics, the pressure gradient and buoyancy force. The budget analysis of vertical momentum flux reveals that the buoyancy term and pressure gradient term are largely balanced and barotropic stability is mainly related to dynamic processes, whereas barotropic instability is generally associated with the processes related to the pressure gradient.

Since only one torrential rainfall event is analyzed and the cloud-resolving model used is $2 \mathrm{D}$, a $3 \mathrm{D}$ model is needed 
to study different torrential rainfall cases in various climate regimes to validate the results of this study.

Acknowledgements. The authors thank W.-K. TAO at NASA/ GSFC for his cloud-resolving model, and the two anonymous reviewers for their constructive comments. This work was supported by the National Natural Science Foundation of China (Grant No. 41475039) and National Key Basic Research and Development Project of China (Grant No. 2015CB953601).

\section{REFERENCES}

Chou, M.-D., and M. J. Suarez, 1994: An efficient thermal infrared radiation parameterization for use in general circulation model. Vol. 3, NASA Tech. Memo. 104606, 85 pp. [Available online at NASA/Goddard Space Flight Center, Code 913, Greenbelt, MD 20771.]

Chou, M.-D., D. P. Kratz, and W. Ridgway, 1991: Infrared radiation parameterizations in numerical climate models. J. Climate, 4, 424-437.

Chou, M.-D., M. J. Suarez, C.-H. Ho, M. M.-H. Yan, and K.T. Lee, 1998: Parameterizations for cloud overlapping and shortwave single-scattering properties for use in general circulation and cloud ensemble models. J. Climate, 11, 202-214.

Corbosiero, K. L., and J. Molinari, 2002: The effects of vertical wind shear on the distribution of convection in tropical cyclones. Mon. Wea. Rev., 130, 2110-2123.

Gao, S. T., and X. F. Li, 2008: Cloud-Resolving Modeling of Convective Processes. Springer, $206 \mathrm{pp}$.

Krueger, S. K., Q. Fu, K. N. Liou, and H.-N. S. Chin, 1995: Improvements of an ice-phase microphysics parameterization for use in numerical simulations of tropical convection. $J$. Appl. Meteor., 34, 281-287.

Lang, S., W.-K. Tao, J. Simpson, R. Cifelli, S. Rutledge, W. Olson, and J. Halverson, 2007: Improving simulations of convective systems from TRMM LBA: Easterly and westerly regimes. $J$. Atmos. Sci., 64, 1141-1164.

Li, X. F., and S. T. Gao, 2012: Precipitation Modeling and Quantitative Analysis. Springer, Dordrecht, 240 pp.

Li, X. F., C.-H. Sui, K.-M. Lau, and M.-D. Chou, 1999: Largescale forcing and cloud-radiation interaction in the tropical deep convective regime. J. Atmos. Sci., 56, 3028-3042.

Li, X. F., C.-H. Sui, and K.-M. Lau, 2002a: Dominant cloud microphysical processes in a tropical oceanic convective system: A 2D cloud resolving modeling study. Mon. Wea. Rev., 130, 2481-2491.

Li, X. F., C.-H. Sui, and K.-M. Lau, 2002b: Interactions between tropical convection and its embedding environment: an energetics analysis of a 2D cloud resolving simulation. J. Atmos. Sci., 59, 1712-1722.

Lin, Y.-L., R. D. Farley, and H. D. Orville, 1983: Bulk parameterization of the snow field in a cloud model. J. Climate Appl. Meteor., 22, 1065-1092.
Pastushkov, R. S., 1975: The effects of vertical wind shear on the evolution of convective clouds. Quart. J. Roy. Meteor. Soc., 101, 281-291.

Robe, F. R., and K. A. Emanuel, 2001: The effect of vertical wind shear on radiative-convective equilibrium states. $J$. Atmos. Sci., 58, 1427-1445.

Rutledge, S. A., and P. Hobbs, 1983: The mesoscale and microscale structure and organization of clouds and precipitation in midlatitude cyclones. VIII: A model for the "seederfeeder" process in warm-frontal rainbands. J. Atmos. Sci., 40 , $1185-1206$.

Rutledge, S. A., and P. V. Hobbs, 1984: The mesoscale and microscale structure and organization of clouds and precipitation in midlatitude cyclones. XII: A diagnostic modeling study of precipitation development in narrow cold-frontal rainbands. J. Atmos. Sci., 41, 2949-2972.

Shen, X. Y., Y. Wang, and X. F. Li, 2011: Effects of vertical wind shear and cloud radiative processes on responses of rainfall to the large-scale forcing during pre-summer heavy rainfall over southern China. Quart. J. Roy. Meteor. Soc., 137, 236-249.

Soong, S.-T., and Y. Ogura, 1980: Response of tradewind cumuli to large-scale processes. J. Atmos. Sci., 37, 2035-2050.

Soong, S.-T., and W.-K. Tao, 1980: Response of deep tropical cumulus clouds to mesoscale processes. J. Atmos. Sci., 37 , 2016-2034.

Sui, C. H., K. M. Lau, W. K. Tao, and J. Simpson, 1994: The tropical water and energy cycles in a cumulus ensemble model. Part I: equilibrium climate. J. Atmos. Sci., 51, 711-728.

Sui, C.-H., X. Li, and K.-M. Lau, 1998: Radiative-convective processes in simulated diurnal variations of tropical Oceanic convection. J. Atmos. Sci., 55, 2345-2357.

Tao, W.-K., and J. Simpson, 1993: The Goddard cumulus ensemble model. Part I: model description. Terrestrial Atmospheric and Oceanic Sciences, 4, 35-72.

Tao, W.-K, J. Simpson, and M. McCumber, 1989: An ice-water saturation adjustment. Mon. Wea. Rev., 117, 231-235.

Ueno, M., 2007: Observational analysis and numerical evaluation of the effects of vertical wind shear on the rainfall asymmetry in the typhoon inner-core region. J. Meteor. Soc. Japan, $\mathbf{8 5}$, $115-136$.

Wang, D. H., X. F. Li, W.-K. Tao, and Y. Wang, 2009: Effects of vertical wind shear on convective development during a landfall of severe tropical storm Bilis (2006). Atmospheric Research, 94, 270-275.

Wu, X. Q., and M. Yanai, 1994: Effects of vertical wind shear on the cumulus transport of momentum: Observations and parameterization. J. Atmos. Sci., 51, 1640-1660.

Xu, K.-M., A. Arakawa, and S. K. Krueger, 1992: The macroscopic behavior of cumulus ensembles simulated by a cumulus ensemble model. J. Atmos. Sci., 49, 2402-2420.

Zhai, G. Q., X. F. Li, P. J. Zhu, H. F. Shen, and Y. Z. Zhang, 2014: Surface rainfall and cloud budgets associated with mei-yu torrential rainfall over eastern China during June 2011. Adv. Atmos. Sci., 31, 1435-1444, doi: 10.1007/s00376-014-3256-7. 